Research Article

\title{
Investigation on the Effect of Probability Distribution on the Dynamic Response of Liquefiable Soils
}

\author{
Juncheng Wang, ${ }^{1}$ Li Zhou $\left(\mathbb{D},{ }^{2}\right.$ Wenzhi Song, ${ }^{3}$ Houle Zhang, ${ }^{1}$ and Yongxin $W u\left(\mathbb{D}{ }^{1}\right.$ \\ ${ }^{1}$ Key Laboratory of Ministry of Education for Geomechanics and Embankment Engineering, \\ College of Civil and Transportation Engineering, Hohai University, Nanjing 210098, China \\ ${ }^{2}$ China Construction Science and Industry Corporation LTD, Shenzhen 518000, China \\ ${ }^{3}$ Shanghai MCC20 Construction Corporation Limited, 2469 Tieli Road, Shanghai 201999, China \\ Correspondence should be addressed to Yongxin Wu; yxwuhhu@163.com
}

Received 15 October 2021; Accepted 19 November 2021; Published 28 December 2021

Academic Editor: Ping Xiang

Copyright (c) 2021 Juncheng Wang et al. This is an open access article distributed under the Creative Commons Attribution License, which permits unrestricted use, distribution, and reproduction in any medium, provided the original work is properly cited.

\begin{abstract}
This study investigated the effect of different probabilistic distributions (Lognormal, Gamma, and Beta) to characterize the spatial variability of shear modulus on the soil liquefiable response. The parameter sensitivity analysis included the coefficient of variation and scale of fluctuation of soil shear modulus. The results revealed that the distribution type had no significant influence on the liquefication zone. In particular, the estimation with Beta distribution is the worst scenario. It illuminated that the estimation with Beta distribution can provide a conservative design if site investigation is absent.
\end{abstract}

\section{Introduction}

It is now well recognized that natural soil properties exhibit spatial variability because of depositional and postdepositional processes. The inherent variability in soil properties has found its place in geotechnical design and has been extensively incorporated in the analysis of slope stability $[1-5]$, foundation bearing capacity $[6,7]$, foundation settlement [8-10], and liquefaction [11-13]. A lognormal distribution has been generally accepted in a geotechnical reliability analysis [14-16] because of its capability to model the randomness of positive soil parameters.

Recent studies proved that different distributions impacted the stochastic properties of soil. Popescu et al. [17] and Jimenez and Sitar [18] performed a series of random finite element analyses with different probability distributions of soil parameters, which has significant effects on the foundation settlement and bearing capacity. Most recently, Wu et al. [19] applied the random finite element method to investigate the effect of different probabilistic distributions on the tunnel convergence and demonstrated the mechanisms of tunnel convergence and the probability of exceeding liquefaction thresholds with different probabilistic distribution types. To date, publications on the application of random field theory to soil dynamic behavior are limited and the impact of probabilistic distribution on the soil liquefiable response has not been clearly defined. Wang et al. [20] investigated the liquefaction response of soil using the spatial variability of the shear modulus by considering different values of the coefficient of variation and the horizontal scale of fluctuation.

In this study, we performed the nonlinear dynamic simulation of the liquefiable response of a sand layer with the water table $1 \mathrm{~m}$ below the ground level under a seismic load using the finite difference program FLAC3D. The finite difference mesh configuration is shown in Figure 1. The soil domain had a length of $40 \mathrm{~m}$ and a height of $10 \mathrm{~m}$, a liquefiable layer of $9 \mathrm{~m}$, and a nonliquefiable layer of $1 \mathrm{~m}$. The Mohr-Coulomb model and the Finn model were used to simulate the nonlinear soil behavior and the accumulation of the pore pressure in sand before the liquefaction triggered by a dynamic load, respectively. The Finn model can consider variations of the volumetric strain and display the increase in excess pore pressure. The relationship between variations of 


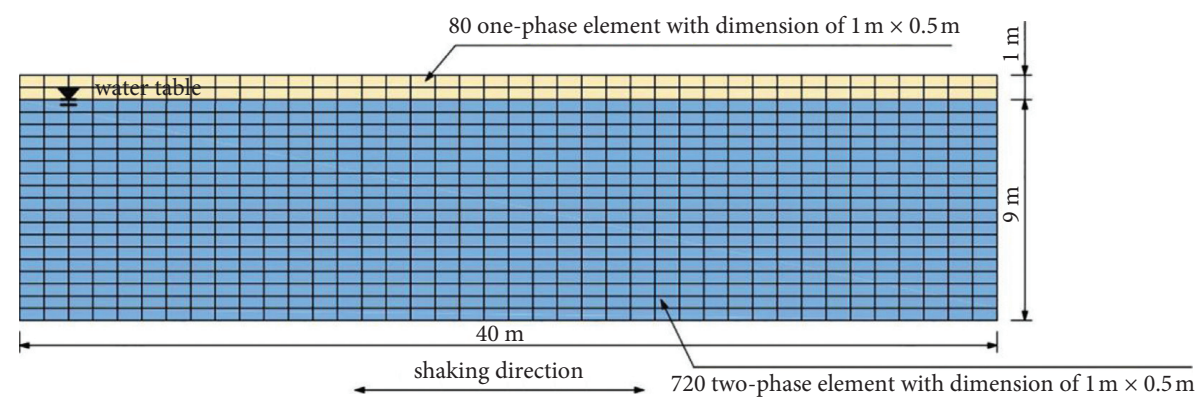

Figure 1: Mesh used in finite difference analysis.

volumetric strain increment $\left(\Delta \varepsilon_{\mathrm{vd}}\right)$ and cycle shearing strains $(r)$ was defined as follows:

$$
\Delta \varepsilon_{\mathrm{vd}}=C_{1}\left(r-C_{2} \varepsilon_{\mathrm{vd}}\right)+\frac{C_{3} \varepsilon_{\mathrm{vd}}^{2}}{r+C_{4} \varepsilon_{\mathrm{vd}}},
$$

where $C_{1}, C_{2}, C_{3}$, and $C_{4}$ are constant coefficients that can be obtained from cyclic triaxial tests. Following the study of Azadi and Hosseini [21], the four values were selected as $0.79,0.52,0.2$, and 0.5 , respectively. Table 1 summarizes the soil parameters in the constitutive model for the deterministic analysis. In the dynamic analysis, the boundaries were used to absorb the reflected waves and enforce the discrete half-space conditions of the numerical model. The free-field boundaries were adopted for the right and left boundaries to simulate the half-space condition. The seismic loading in the horizontal direction was applied at the bottom boundary which was assumed to be rigid.

In the stochastic analyses, the shear modulus $G$ was assumed to be random variable and generated with the spectral representation method, which was recently developed by Shu et al. [7]. Three probabilistic distributions, including lognormal, Beta, and Gamma, were applied to model the spatial variability of $G$, with a mean $\mu_{G}=20 \mathrm{MPa}$ and $\mathrm{CoV}_{G}=0.1,0.3$, and 0.5. A 2D exponential correlation function [22] was adopted with the horizontal and vertical spatial correlation lengths $\delta_{x}=6$ and $60 \mathrm{~m}$ and $\delta_{y}=6 \mathrm{~m}$, respectively. 200 sets of Monte Carlo realizations were undertaken for each combination of a distribution type, a scale of fluctuation, and a $\mathrm{CoV}_{G}$.

\section{Results and Discussion}

2.1. Area of Liquefied Zone $A_{80}$. Figure 2 plots the mean of $A_{80}\left(\mu_{A_{80}}\right)$ varying with the time history curve with different stochastic distributions. Following Popescu et al. [23], $A_{80}(t)$ from one finite difference computation is defined as

$$
A_{80}(t)=\frac{\operatorname{area}\left(u(t) / \sigma_{\nu 0}>0.8\right)}{\text { area }(\text { total })},
$$

where $\sigma_{\nu 0}{ }^{\prime}$ and $\mu(t)$ are the initial effective stress at a specific location and the excess pore water pressure at the time instant $t$ after the earthquake, respectively.

For the set of $\delta_{x}$ in this study, the difference between the distribution types merely led to a minor diversity of the peak $\mu_{A_{80}}$ by the random shear modulus $\mathrm{CoV}_{G}=0.1$. However, the
TABle 1: Summary of soil parameters.

\begin{tabular}{lc}
\hline Parameters & Value \\
\hline Shear modulus, $G: \mathrm{MPa}$ & 20 \\
Total unit weight, $\gamma: \mathrm{kN} / \mathrm{m}^{3}$ & 26.6 \\
Poisson's ratio, $\nu$ & 0.35 \\
Permeability coefficient, $k: \mathrm{m} / \mathrm{s}$ & $2.64 \times 10^{-4}$ \\
Porosity, $N$ & 0.435 \\
\hline
\end{tabular}

peak $\mu_{A_{80}}$ by the Beta distribution was smaller than that by the Lognormal and Gamma distributions with $\mathrm{CoV}_{G}=0.3$ and $\mathrm{CoV}_{G}=0.5$ (Figures 2(b)-2(f)). In addition, the greatest peak $\mu_{A_{80}}$ was correlated with the $G$ conformed to the Lognormal distribution in these cases.

From the perspective of the decreasing rate of $A_{80}$, the residual of $A_{80}$, and the sensitivity of $A_{80}$ to instantaneous seismic loading, it was found that the influence of the different probability distributions on the dynamic liquefaction results was irregular, considering the results of the nonGaussian probability distributions. However, in general, the differences among the calculated results from the three probability distributions became more obvious with the increase in $\mathrm{CoV}_{G}$. Figure 2 presents that the irregular dynamic liquefaction results from different probability distributions, in terms of the residual $A_{80}$ and the response of $A_{80}$ to instantaneous seismic loading. Additionally, the increase in $\mathrm{CoV}_{G}$ can amplify the impact from the probability distribution.

2.2. Excess Pore Water Pressure Ratios Q. The liquefication index was calculated from the mean excess pore water pressure ratio in the horizontal direction and of the form for one simulation:

$$
\begin{aligned}
Q(z, t) & =\frac{1}{n} \sum_{x} r(x, z, t), \\
r(x, z, t) & =\frac{u(x, z, t)}{\sigma_{\nu 0}},
\end{aligned}
$$

where $x$ and $z$ are the horizontal and vertical coordinates of the central point of one finite difference element, respectively; $r(x, z, t)$ is the excess pore water pressure ratio at the central point $(x, z)$ at $t$-th second after the earthquake; $\sigma_{v 0}^{\prime}$ is the initial effective stress in the vertical direction; $n$ was set to be 40 in this study, which represents the element number of 

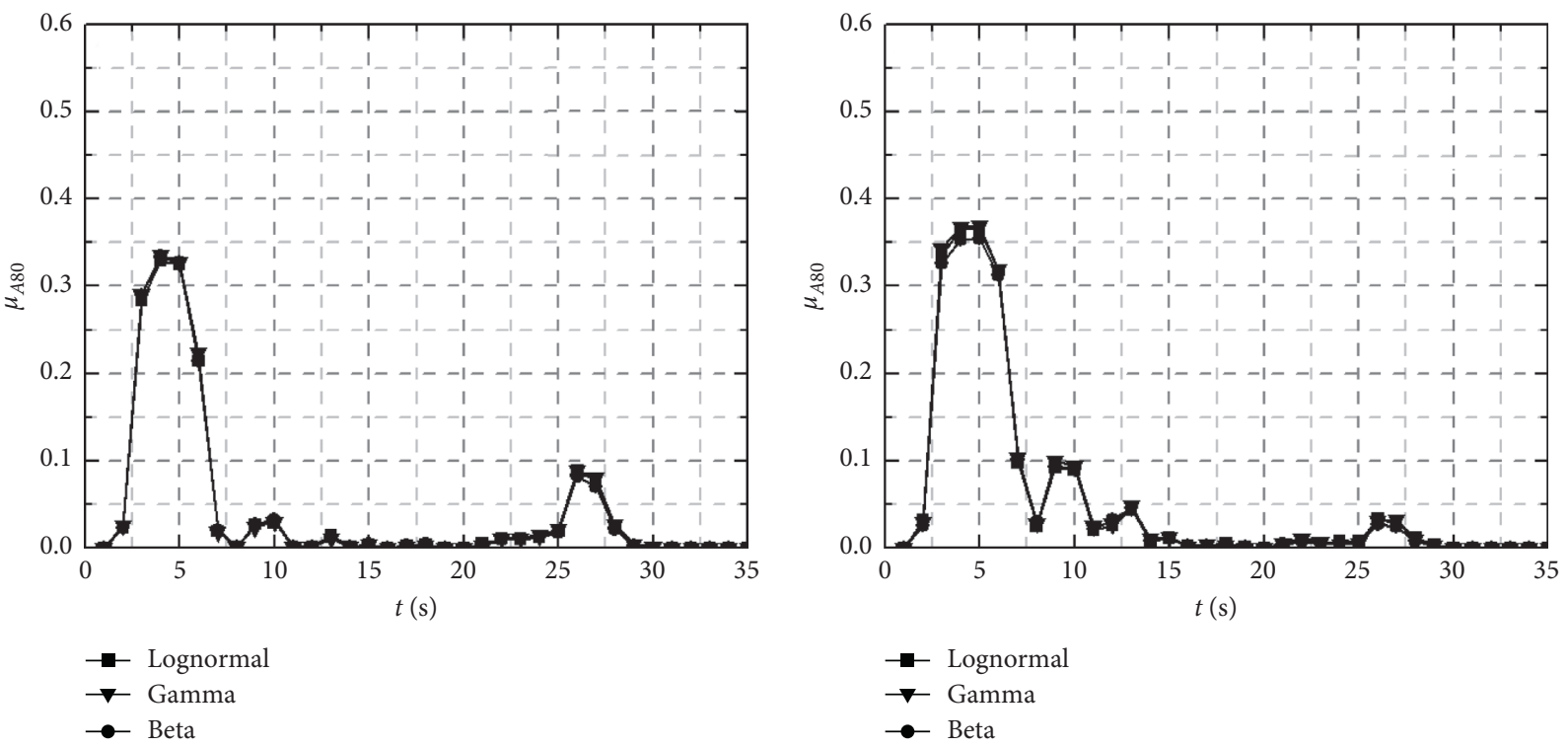

(a)
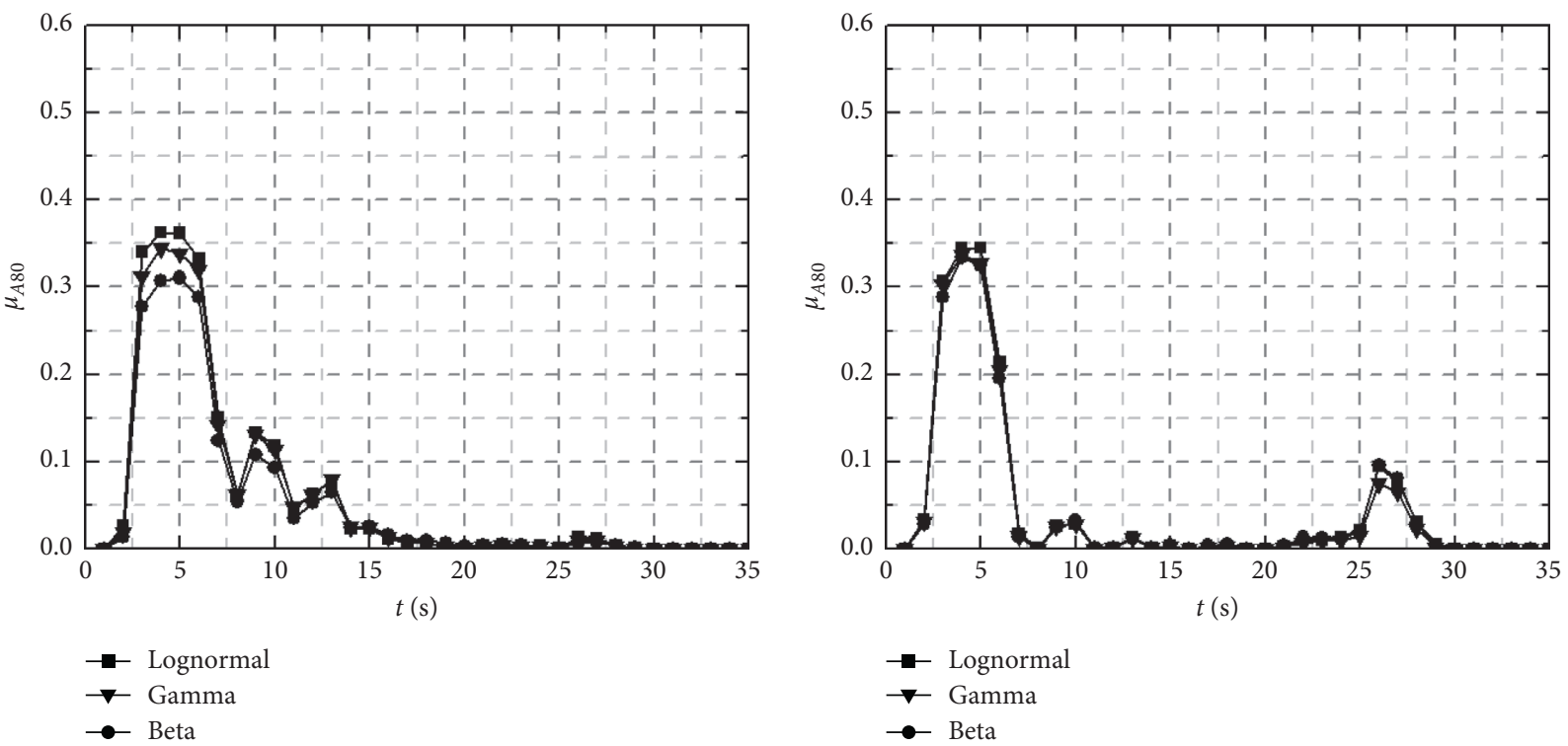

(c)

(d)

FIgUre 2: Continued. 


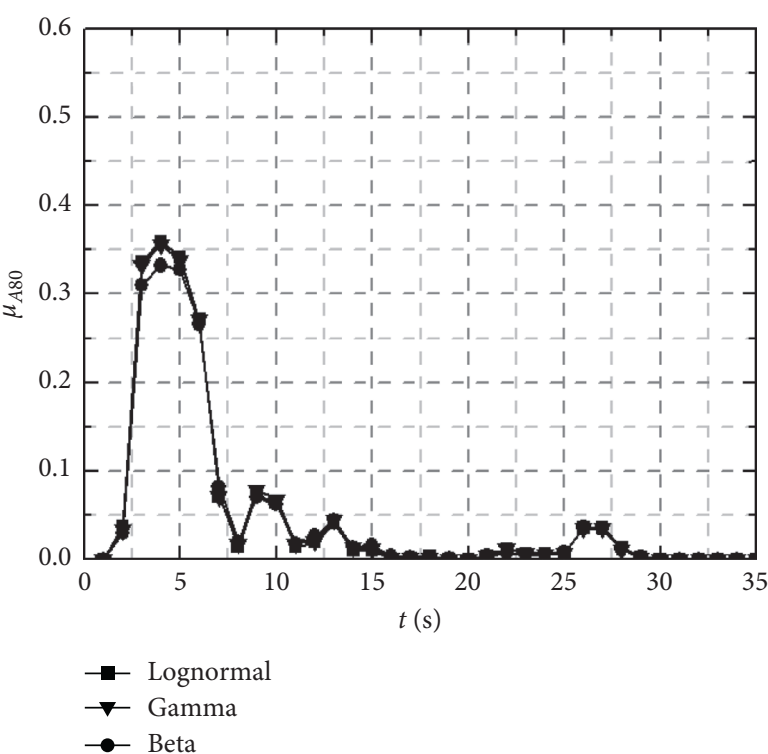

(e)

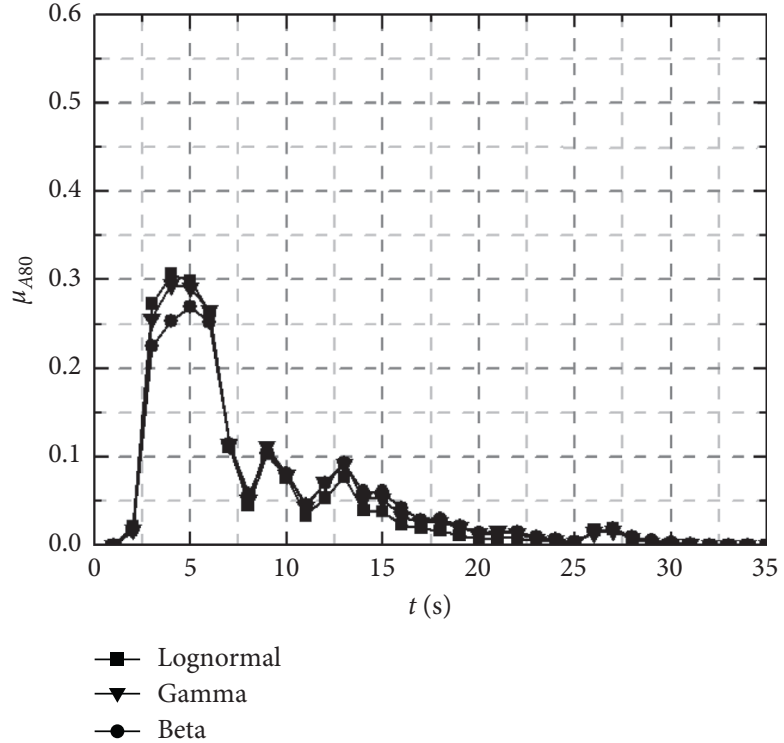

(f)

FIgURe 2: Time history curve of mean liquefaction range with different distributions: (a) $\delta_{x}=6 \mathrm{~m}$ and $\mathrm{CoV} \mathrm{V}_{G}=0.1 ;(\mathrm{b}) \delta_{x}=6 \mathrm{~m}$ and $\mathrm{CoV}_{G}=0.3$; (c) $\delta_{x}=6 \mathrm{~m}$ and $\mathrm{CoV}_{G}=0.5$; (d) $\delta_{x}=60 \mathrm{~m}$ and $\mathrm{CoV}_{G}=0.1$; (e) $\delta_{x}=60 \mathrm{~m}$ and $\mathrm{CoV}_{G}=0.3$; (f) $\delta_{x}=60 \mathrm{~m}$ and $\mathrm{CoV}_{G}=0.5$.

the finite difference model in the horizontal direction; and $Q(z, t)$ reflects the average excess pore water pressure ratio at the depth of $z$ at $t$-th second after the earthquake. Due to the fact that large accumulation of pore water pressure might occur in the deep soil layer, this study paid close attention to the variation of $Q$ at $z=7.25 \mathrm{~m}$.

Figure 3 presents the time history curves of the mean excess pore water pressure ratio $\left(\mu_{\mathrm{Q}}\right)$ at $z=7.25 \mathrm{~m}$ with different probabilistic distributions. In the case with $\mathrm{CoV}_{G}=0.1$ and $\delta_{x}=6 \mathrm{~m}$ or $60 \mathrm{~m}, \mu_{Q}$ with varying types of distribution presents a similar trend with the seismic load imposed to the soil layer (Figures 3(a) and 3(d)). However, with the increased $\mathrm{CoV}_{G}$, the rebound amplitude of $\mu_{Q}$ with different probabilistic distributions gradually declined (Figures 3(b)-3(f)). In addition, $\mu_{\mathrm{Q}}$ with the Beta distribution was slightly smaller than that with the Lognormal and Gamma distributions when the $\mathrm{CoV}_{G}$ is 0.3 and 0.5 , and its dissipation rate of excess pore water pressure (in terms of the slope of the descending part of $\mu_{Q}$ curve) was smaller than that with the Lognormal distribution and Gamma distribution.

Figure 3 also shows that $\mu_{\mathrm{Q}}$ dissipated after the occurrence of the peak $\mu_{O}$ appeared around $t=4 \mathrm{~s}$. Table 2 summarizes $\mu_{Q}$ with shear modulus by different distributions after $7 \mathrm{~s}$ and $35 \mathrm{~s}$ occurrence of the earthquake. Table 3 tabulates the dissipation rate of pore water pressure, which was depicted from the descending section of the $\mu_{\mathrm{Q}}$ time history curve. In general, the dissipation rate of $\mu_{Q}$ increased with the increase in $\mathrm{CoV}_{G}$, and this increasing trend was affected by the distribution type. For instance, the amplification was $16.11 \%$ for the Beta distribution as $\mathrm{CoV}_{G}$ extended from 0.1 to 0.5 , which was greater compared with that with the Gamma and Lognormal distributions.
2.3. Ground Displacement $D$. In this section, the maximum surface ground horizontal movement $\left(D_{x}(t)_{\max }\right)$ in Equation (4) and settlement $\left(D_{z}(t)_{\max }\right)$ in Equation (5) were taken to evaluate the influence of liquefaction by earthquake, respectively:

$$
\begin{gathered}
D_{x}(t)_{\max }=\left\{D_{x, z=0}(t)-D_{x, z=10}(t)\right\}_{\max } \\
D_{z}(t)_{\max }=\left\{D_{z}(t)_{\max }-D_{z}(t)_{\min }\right\}_{\max },
\end{gathered}
$$

where $D_{x, z=0}(t)$ and $D_{x, z=10}(t)$ represent the horizontal displacements at surface and bottom at the horizontal coordinate $x$ in the soil domain and $D_{z}(t)_{\max }$ and $D_{z}(t)_{\min }$ represent the maximum and minimum settlement at $t$-th second after the earthquake.

Figure 4 plots the time history curve of mean ground horizontal displacement $\left(\mu_{D_{x}}\right)$ with different probabilistic distributions. Similar time history curves of $\mu_{D_{x}}$ for different distributions were obtained provided $\mathrm{CoV}_{G}=0.1$, indicating that the distribution types had little influence on the ground horizontal displacement (Figures 4(a) and 4(d)). The differences between $\mu_{D_{x}}$ became pronounced with the increase in $\mathrm{CoV}_{G}$. It was worth noting that $\mu_{D}$ with the Beta distribution was always the largest, while $\mu_{D_{x}}$ with Lognormal distribution was the smallest.

As expected, the probability distributions also had certain impact on the standard deviation of the horizontal displacement $\left(\mu_{D_{x}}\right)$ (Figure 5). The difference of $\mu_{D_{x}}$ gradually increased with the increase in $\mathrm{CoV}_{G}$, referring that the effect of different distribution on $\mu_{D_{x}}$ enhanced with the increase in $\mathrm{CoV}_{G}$. If $\mathrm{CoV}_{G}$ is 0.3 or 0.5 , it was obvious that $\mu_{D_{x}}$ with the Beta distribution was always greater than that with the Lognormal and Gamma distributions. 

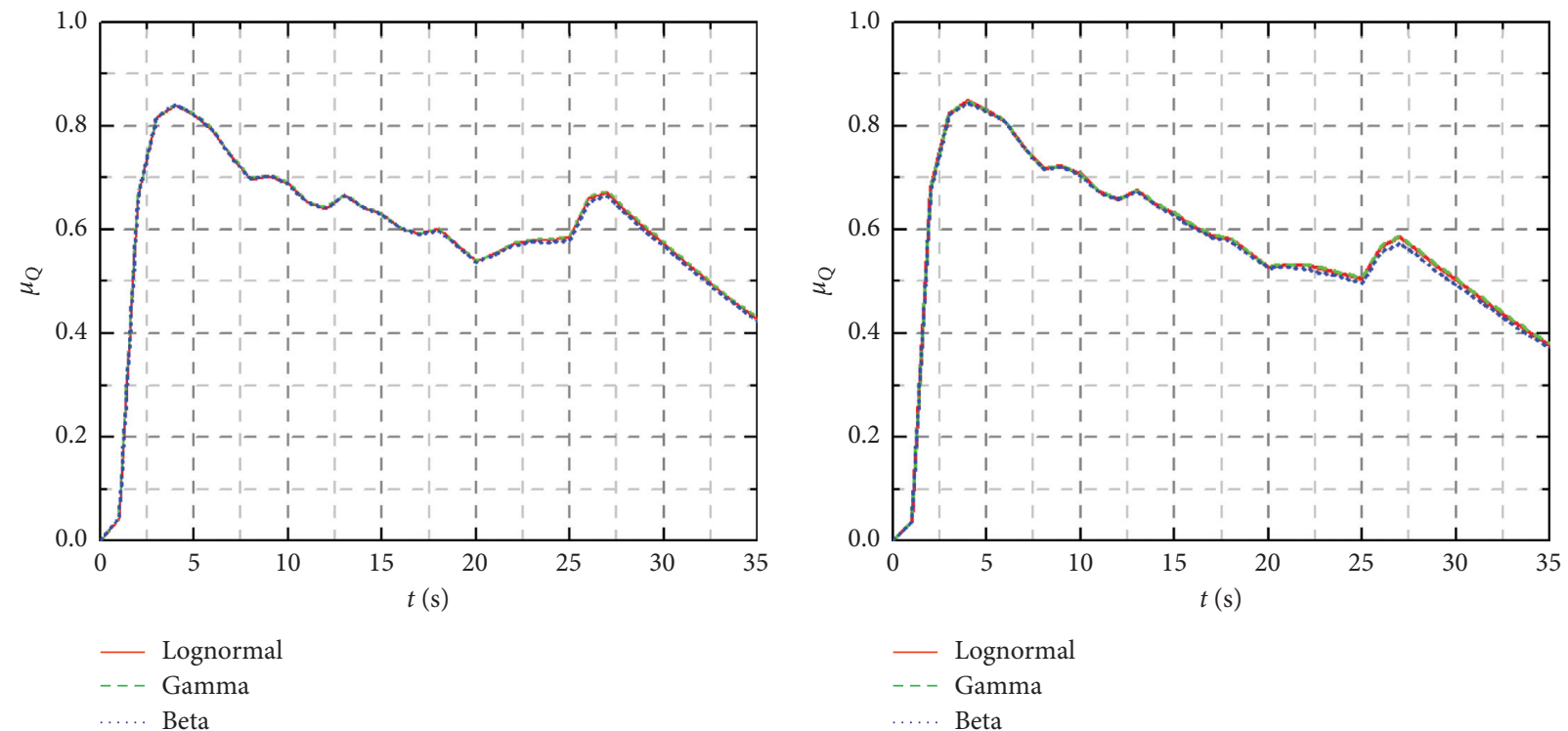

(a)
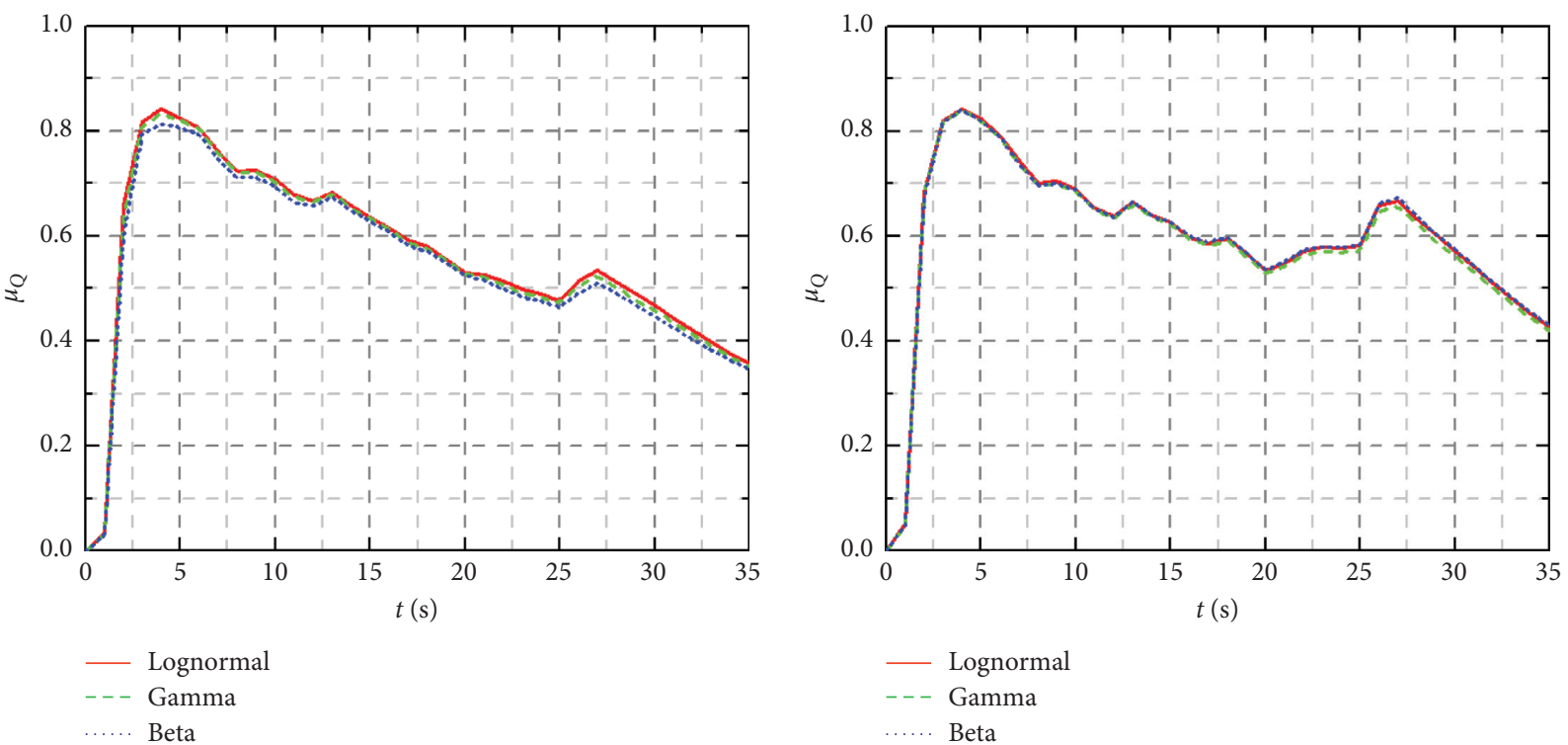

(c)

(d)

Figure 3: Continued. 


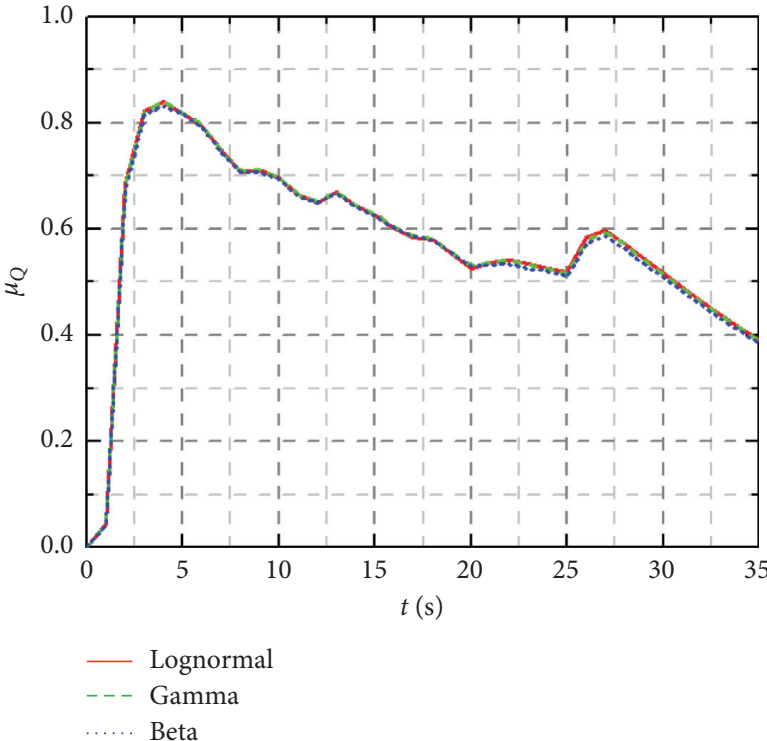

(e)

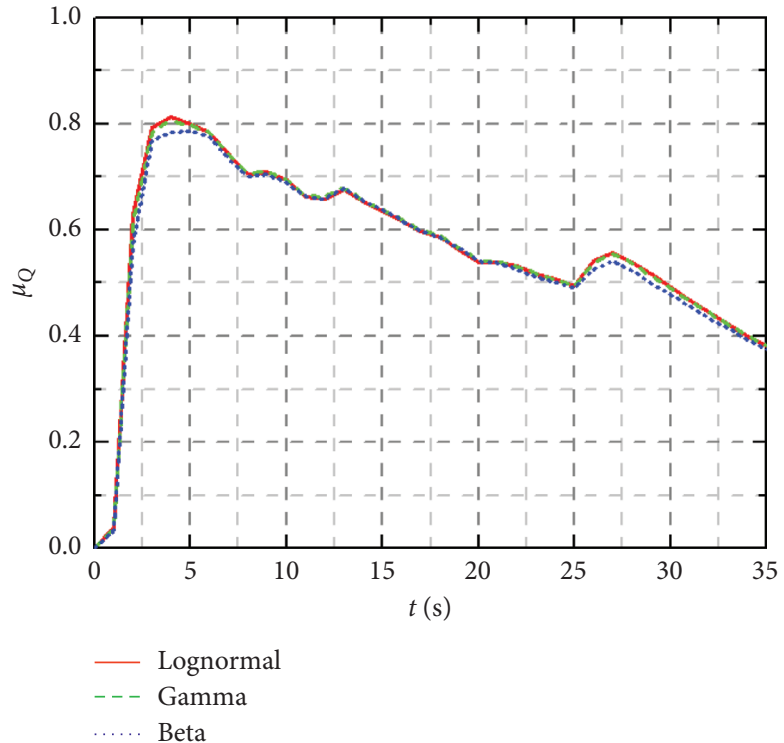

(f)

Figure 3: Time history curves of $\mu_{Q}$ at $(\mathrm{z})=7.25 \mathrm{~m}$ with different distributions: (a) $\delta_{x}=6 \mathrm{~m}$ and $\mathrm{CoV}_{G}=0.1 ;$ (b) $\delta_{x}=6 \mathrm{~m}$ and CoV $=0.3$; (c) $\delta_{x}=6 \mathrm{~m}$ and $\mathrm{CoV}_{G}=0.5$; (d) $\delta_{x}=60 \mathrm{~m}$ and $\mathrm{CoV}_{G}=0.1$; (e) $\delta_{x}=60 \mathrm{~m}$ and $\mathrm{CoV}_{G}=0.3$; (f) $\delta_{x}=60 \mathrm{~m}$ and $\mathrm{CoV}_{G}=0.5$.

TABLE 2: Summary of $\mu_{\mathrm{Q}}$ at $z=7.25 \mathrm{~m}$ and $t=7$ and $35 \mathrm{~s}\left(10^{-2}\right)$.

\begin{tabular}{|c|c|c|c|c|c|c|c|}
\hline \multirow{2}{*}{$\delta_{x}(\mathrm{~m})$} & \multirow{2}{*}{ Probabilistic distribution } & \multicolumn{2}{|c|}{$\mathrm{CoV}_{G}=0.1$} & \multicolumn{2}{|c|}{$\mathrm{CoV}_{G}=0.3$} & \multicolumn{2}{|c|}{$\mathrm{CoV}_{G}=0.5$} \\
\hline & & $t=7 \mathrm{~s}$ & $t=35 \mathrm{~s}$ & $t=7 \mathrm{~s}$ & $t=35 \mathrm{~s}$ & $t=7 \mathrm{~s}$ & $t=35 \mathrm{~s}$ \\
\hline \multirow{3}{*}{6} & Lognormal & 73.96 & 42.76 & 75.76 & 37.83 & 76.00 & 35.72 \\
\hline & Gamma & 74.25 & 43.04 & 75.70 & 38.07 & 75.65 & 35.13 \\
\hline & Beta & 74.00 & 42.37 & 75.60 & 37.22 & 74.58 & 34.45 \\
\hline \multirow{3}{*}{60} & Lognormal & 74.23 & 42.72 & 74.75 & 39.13 & 74.20 & 38.10 \\
\hline & Gamma & 73.88 & 41.96 & 74.75 & 39.02 & 74.12 & 38.23 \\
\hline & Beta & 73.92 & 42.97 & 74.48 & 38.52 & 73.42 & 37.49 \\
\hline
\end{tabular}

TABLE 3: Variation of dissipation rate of $\mu_{\mathrm{Q}}\left(10^{-3} \times \mathrm{s}^{-1}\right)$ at $z=7.25 \mathrm{~m}$.

\begin{tabular}{|c|c|c|c|c|c|}
\hline \multirow{2}{*}{$\delta_{x}(\mathrm{~m})$} & \multirow{2}{*}{ Probabilistic distribution } & \multicolumn{3}{|c|}{$\mathrm{CoV}_{G}$} & \multirow{2}{*}{ Amplification (\%) } \\
\hline & & 0.1 & 0.3 & 0.5 & \\
\hline \multirow{3}{*}{6} & Lognormal & 11.14 & 13.55 & 14.39 & 29.17 \\
\hline & Gamma & 11.15 & 13.44 & 14.47 & 29.78 \\
\hline & Beta & 11.30 & 13.71 & 14.33 & 26.81 \\
\hline \multirow{3}{*}{60} & Lognormal & 11.25 & 12.72 & 12.89 & 14.58 \\
\hline & Gamma & 11.40 & 12.76 & 12.82 & 12.46 \\
\hline & Beta & 11.05 & 12.84 & 12.83 & 16.11 \\
\hline
\end{tabular}

Figure 6 shows the impact of $\mathrm{CoV}_{G}$ on $\mu_{D_{x}}$ with different distributions at $t=35 \mathrm{~s}$. In general, an increase in $\mathrm{CoV}_{G}$ was corresponding with the increase in $\mu_{D_{x}}$ with different distributions. The obtained $\mu_{D_{x}}$ with Beta distribution was greater than that with the Gamma and Lognormal distributions. Moreover, a larger $\delta_{x}$ correlated with a greater $\mu_{D_{x, \max }}$ provided with the same distribution and $\mathrm{CoV}_{G}$ (Figures 6(a) and 6(b)). This finding highlighted that the worst scenario was covered by the shear modulus with Beta distribution. It illuminated that the estimation with Beta distribution is capable to provide a conservative evaluation if site investigation is absent.

The time history curves of mean and standard deviation of settlement $\left(\mu_{D_{z}}\right.$ and $\left.\sigma_{D_{z}}\right)$ are shown in Figures 7 and 8, respectively. The influences of the distributions of $G$ on $\mu_{D_{z}}$ and $\sigma_{D_{z}}$ were similar to those on $\mu_{D_{x}}$ and $\sigma_{D_{x}}$. The differences between $\mu_{D_{z}}$ and $\sigma_{D_{z}}$ with different distributions were insignificant if $\mathrm{CoV}_{G}=0.1$, which implied that the distributions had small impact on the settlement. Nonetheless, the difference was positively correlated with $\mathrm{CoV}_{G}$. For example, 

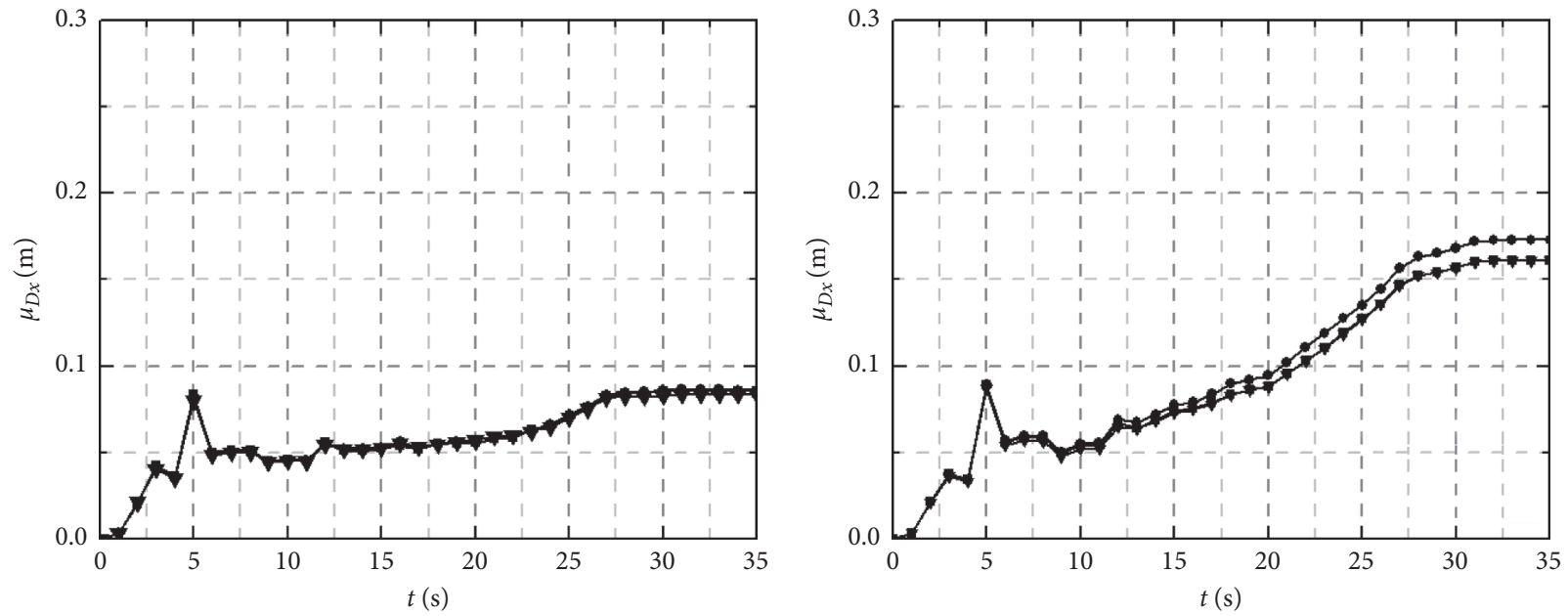

$$
\begin{aligned}
& \rightarrow \text { Lognormal } \\
& \rightarrow-\text { Gamma } \\
& \rightarrow \text { Beta }
\end{aligned}
$$$$
\begin{aligned}
& \longrightarrow \text { Lognormal } \\
& \rightarrow-\text { Gamma } \\
& \longrightarrow \text { Beta }
\end{aligned}
$$

(a)
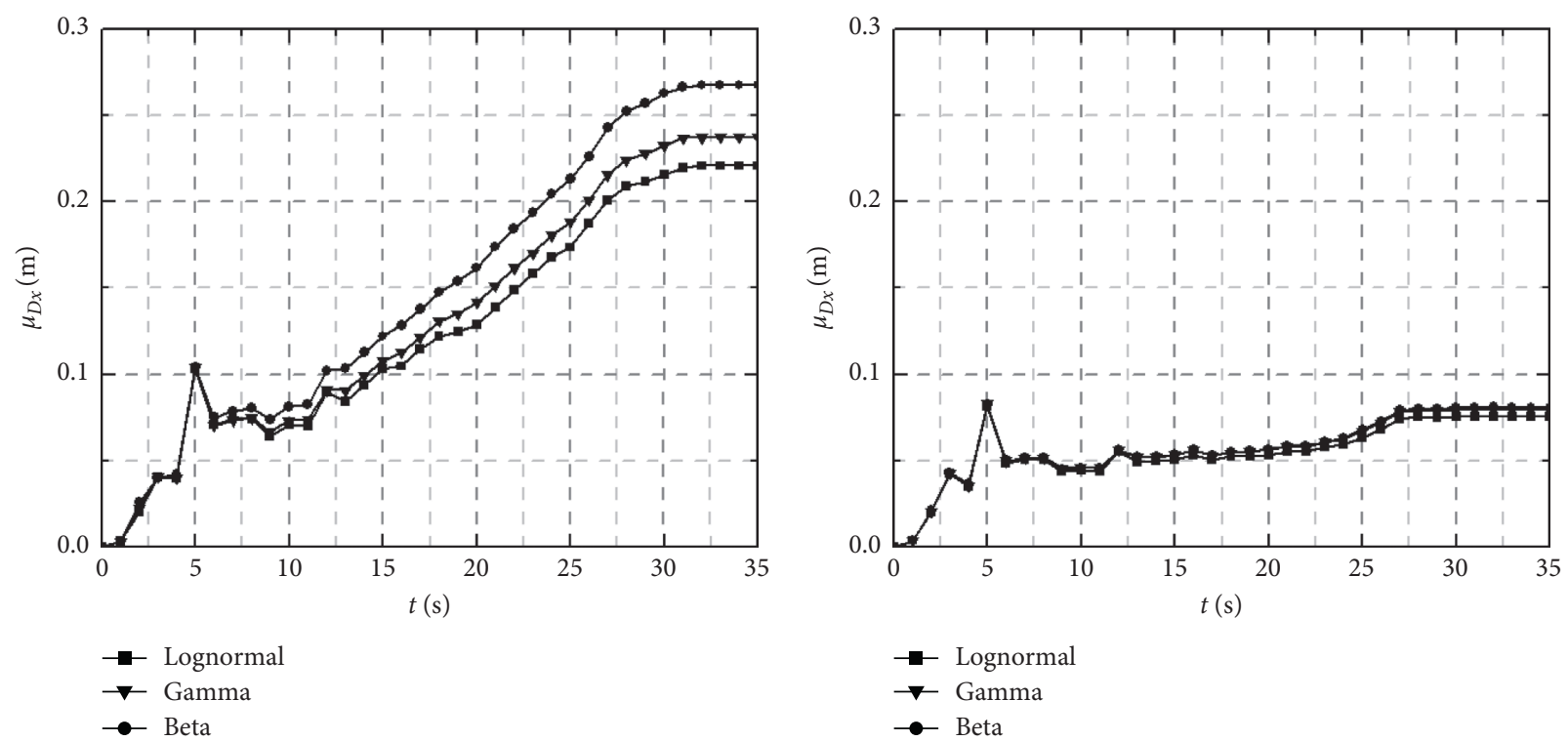

(c)

(d)

Figure 4: Continued. 


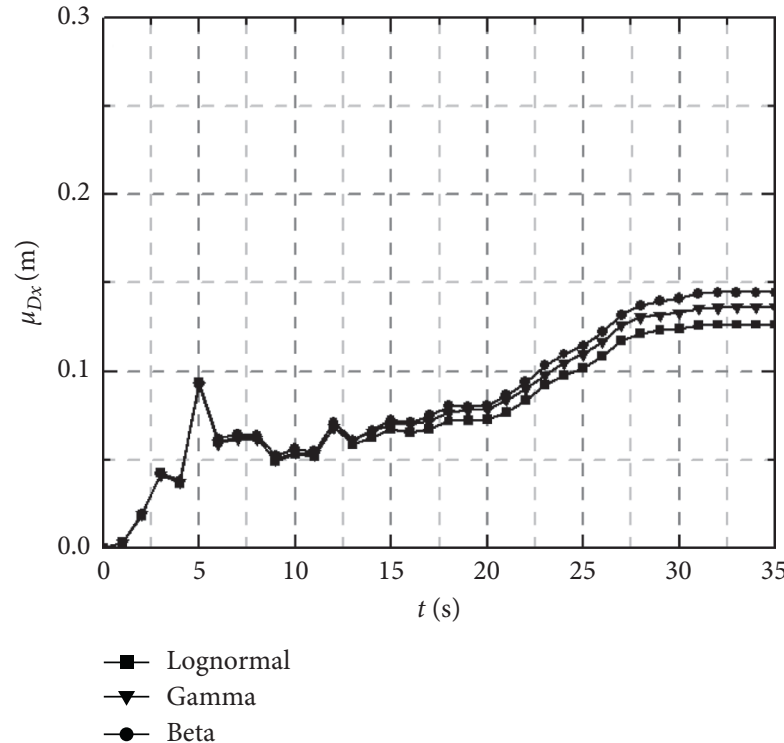

(e)

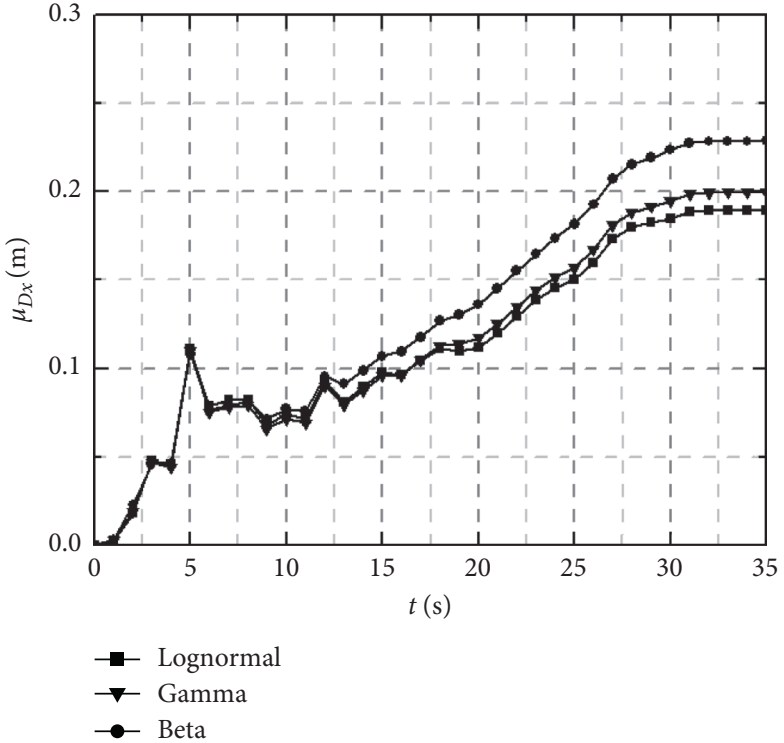

(f)

FIGURE 4: Time history curve of mean ground horizontal displacement $\left(\mu_{D}\right)$ with different distributions: (a) $\delta_{x}=6 \mathrm{~m}$ and CoV $\mathrm{V}_{G}=0.1 ;(\mathrm{b})$ $\delta_{x}=6 \mathrm{~m}$ and $\mathrm{CoV}_{G}=0.3$; (c) $\delta_{x}=6 \mathrm{~m}$ and $\mathrm{CoV}_{G}=0.5$; (d) $\delta_{x}=60 \mathrm{~m}$ and $\mathrm{CoV}_{G}=0.1$; (e) $\delta_{x}=60 \mathrm{~m}$ and $\mathrm{CoV}_{G}=0.3$; (f) $\delta_{x}=60 \mathrm{~m}$ and $\mathrm{CoV}_{G}=0.5$.

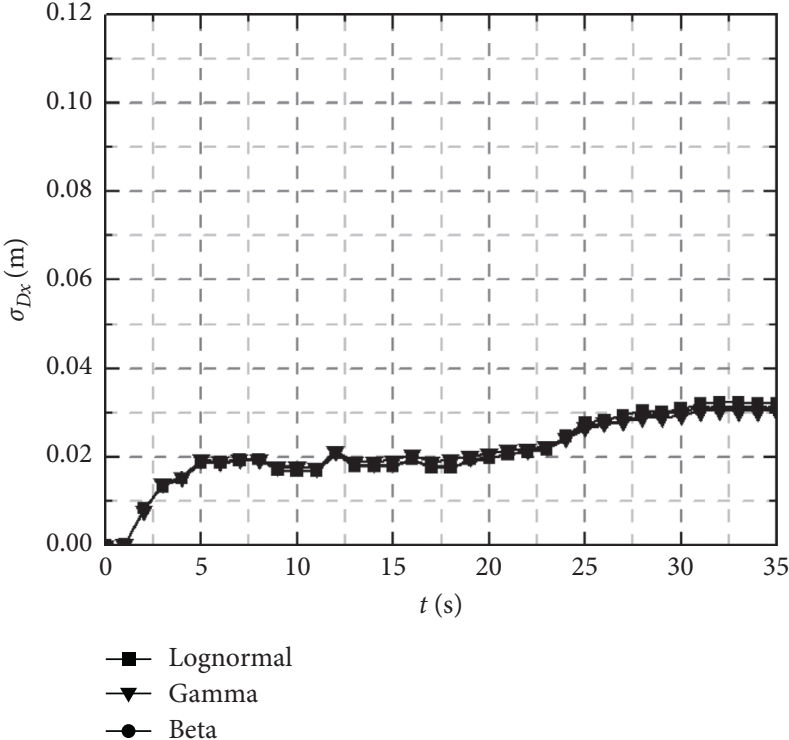

(a)

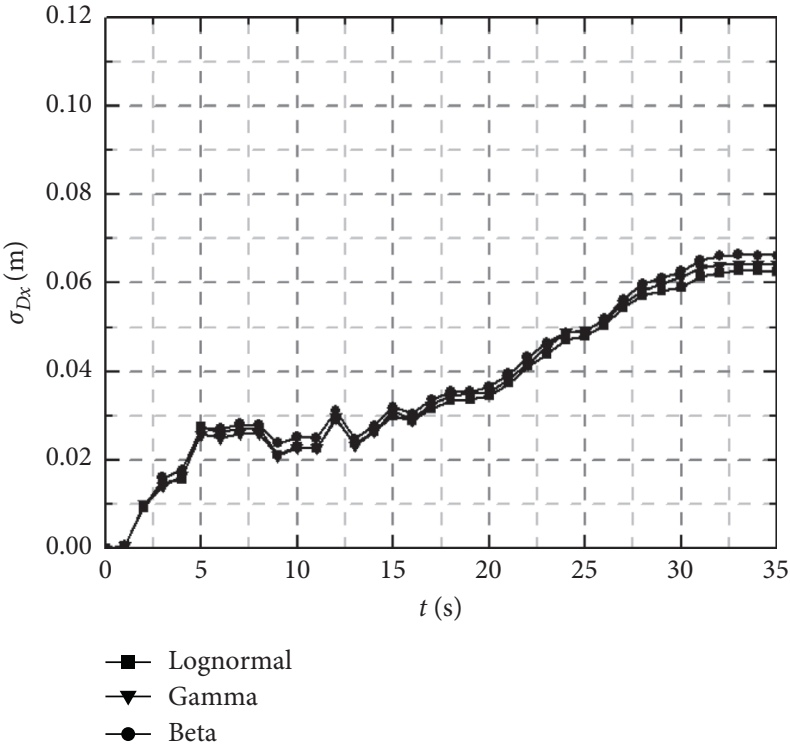

(b)

Figure 5: Continued. 

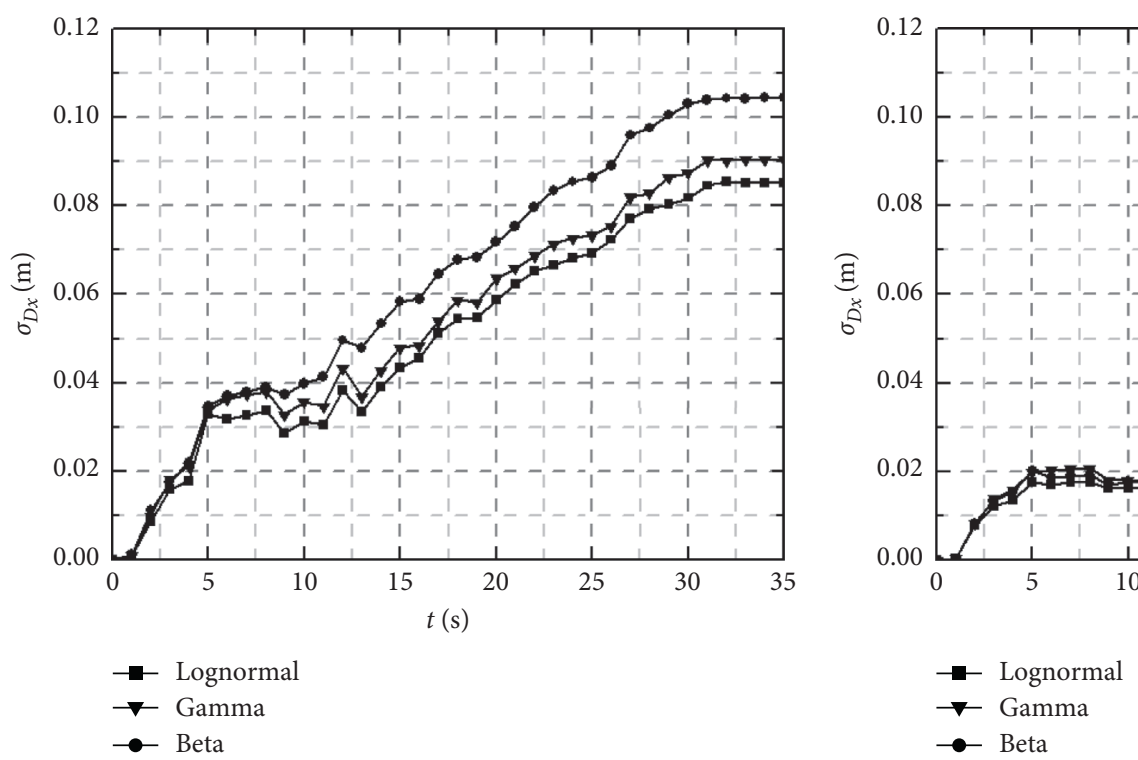

(c)
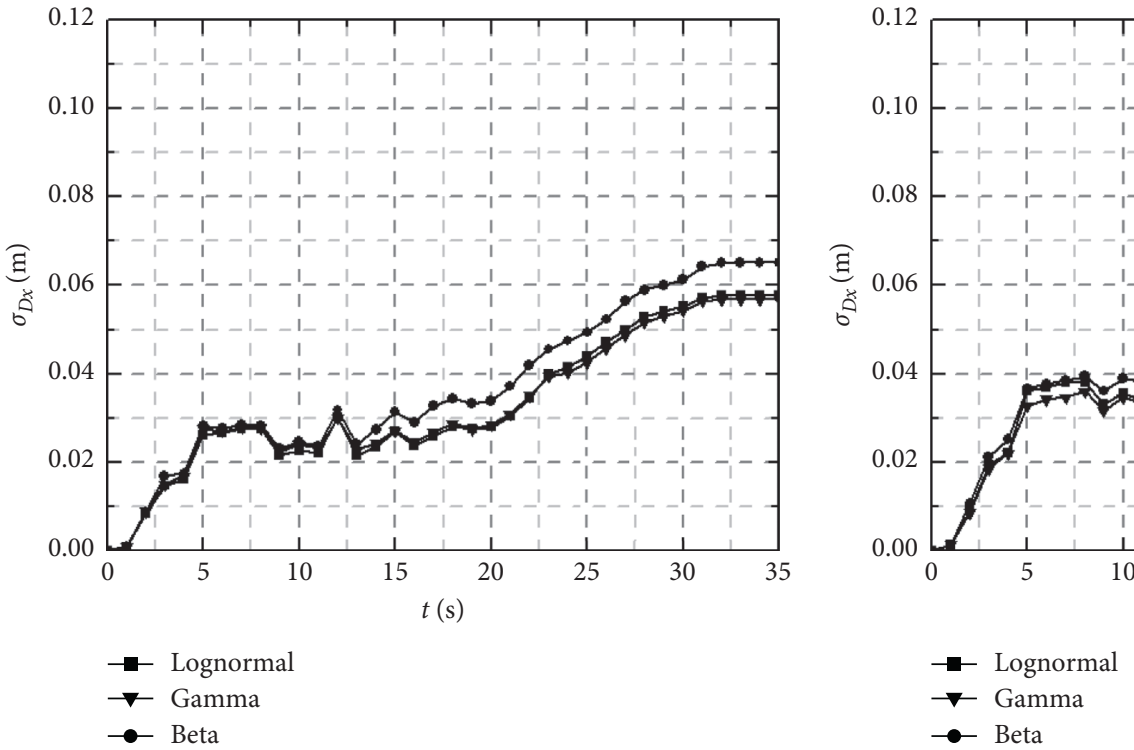

(e)

(f)

Figure 5: Time history curve of standard deviation of ground horizontal displacement $\left(\mu_{D_{x}}\right)$ with different distributions: (a) $\delta_{x}=6 \mathrm{~m}$ and $\mathrm{CoV}_{G}=0.1$; (b) $\delta_{x}=6 \mathrm{~m}$ and $\mathrm{CoV}_{G}=0.3$; (c) $\delta_{x}=6 \mathrm{~m}$ and $\mathrm{CoV}_{G}=0.5 ;$ (d) $\delta_{x}=60 \mathrm{~m}$ and $\operatorname{CoV}_{G}=0.1 ;$ (e) $\delta_{x}=60 \mathrm{~m}$ and $\mathrm{CoV}_{G}=0.3$; (f) $\delta_{x}=60 \mathrm{~m}$ and $\mathrm{CoV}_{G}=0.5$.

with a given $\delta_{x}$ of $6 \mathrm{~m}$ and $\mathrm{CoV}_{G}=0.3, \mu_{D_{z}}$ with the Beta distribution was $7.81 \%$ and $7.28 \%$ larger than that with Gamma distribution and Lognormal distribution. If $\mathrm{CoV}_{G}$ was 0.5 , the results enhanced $20.51 \%$ and $35.89 \%$, respectively. It addresses the conclusion that the influence of the distributions on $\mu_{D_{z}}$ and $\sigma_{D_{z}}$ increased with the increase in
$\mathrm{CoV}_{G}$. The settlement obtained from the random fields obeying Beta distribution was greater and more dispersive than that calculated by the Lognormal distribution and Gamma distribution.

Figure 9 shows the relationship between $\mu_{D_{2} \text { max }}$ and $\mathrm{CoV}_{G}$. The distribution type had a similar impact on 


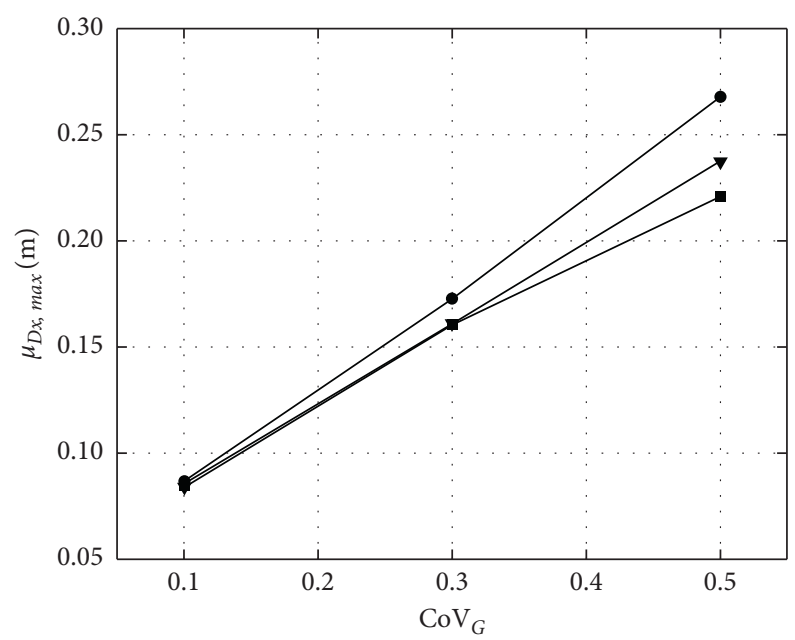

- Lognormal

$\rightarrow$ Gamma

$\rightarrow$ Beta

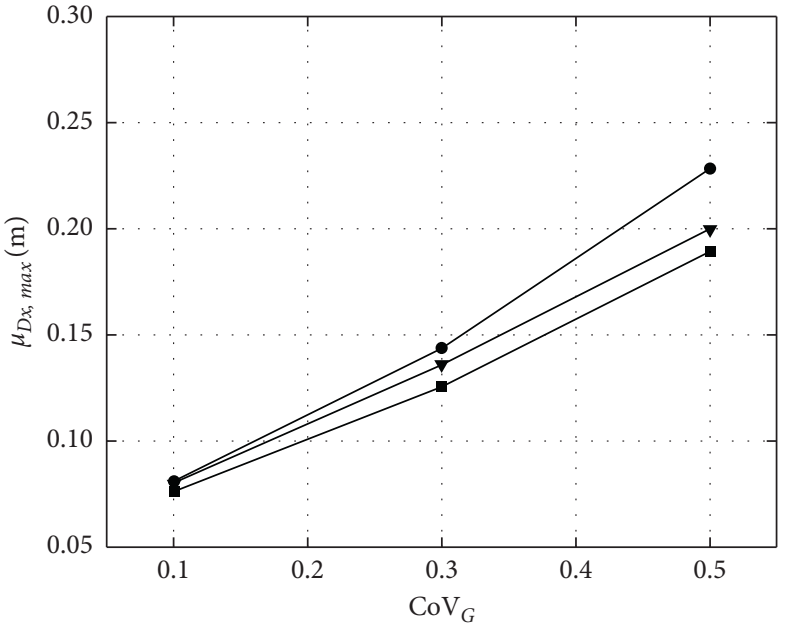

- Lognormal

$\rightarrow$ Gamma

$\rightarrow$ Beta

(a)

(b)

Figure 6: Variation of $\mu_{D_{x, \max }}$ as a function of $\mathrm{CoV}_{G}$ : (a) $\delta_{x}=6 \mathrm{~m}$ and (b) $\delta_{x}=60 \mathrm{~m}$.
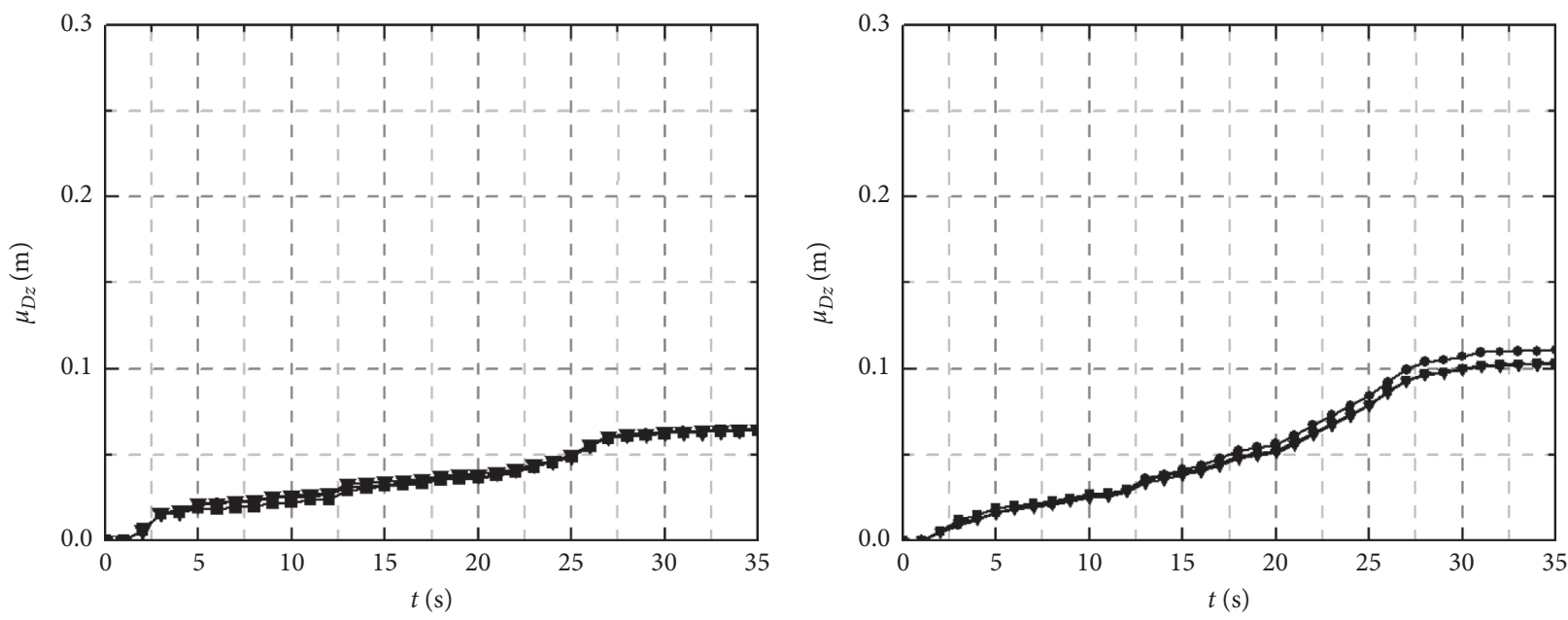

$\rightarrow$ Lognormal
$\rightarrow-$ Gamma
$\rightarrow$ Beta

- Lognormal

$\rightarrow$ Gamma

$\bullet$ Beta

(a)

(b)

Figure 7: Continued. 

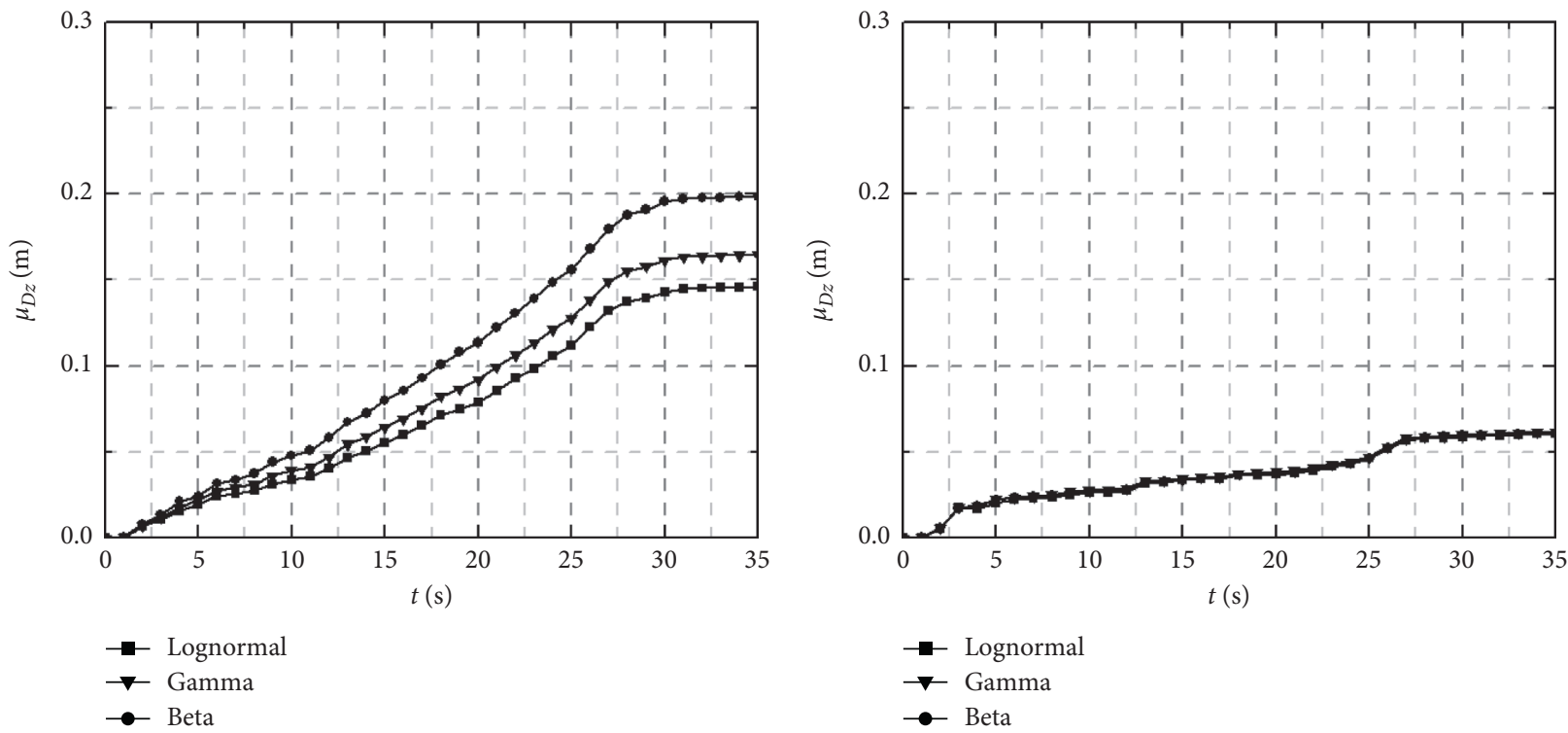

(c)
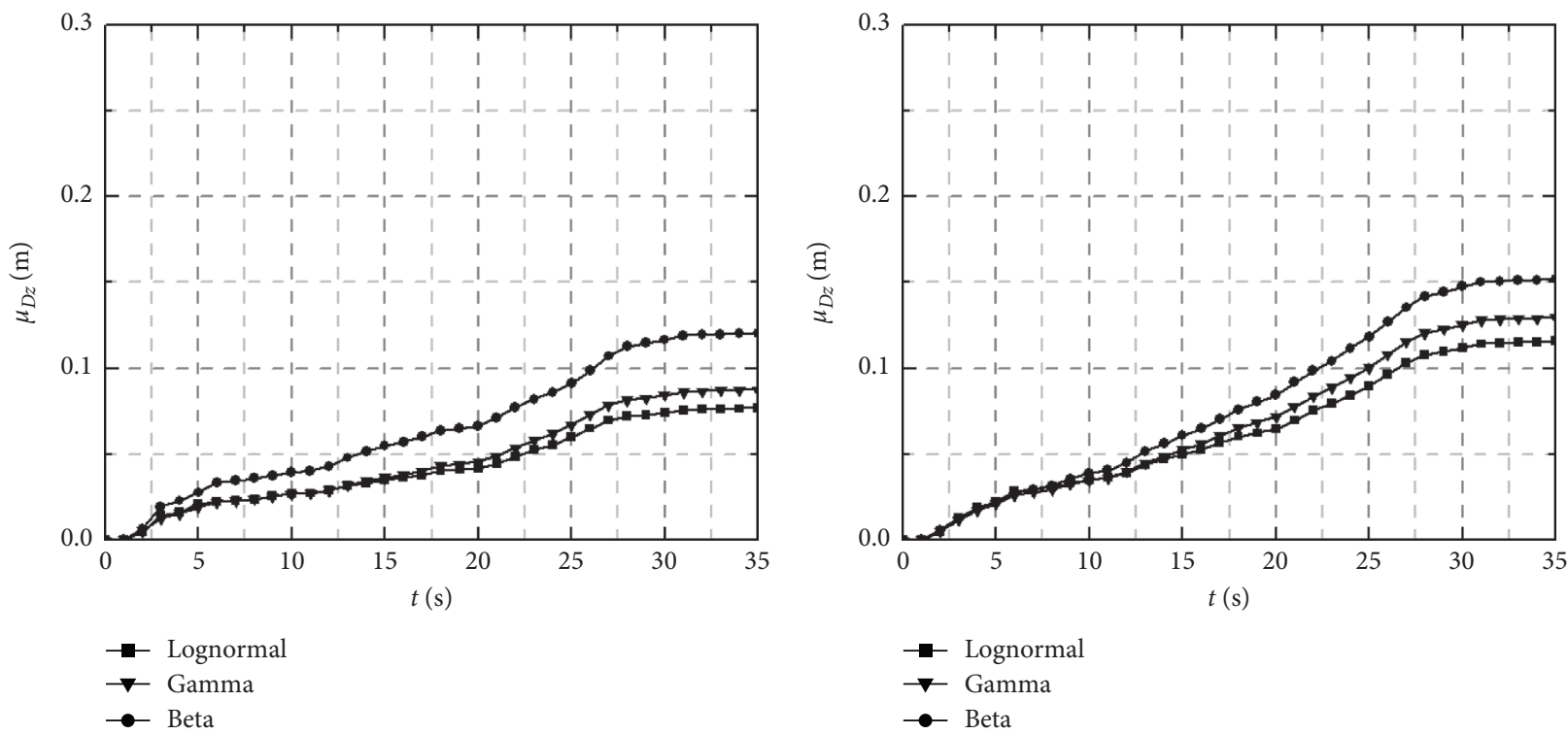

(e)

(f)

Figure 7: Time history curve of $\mu_{D_{z}}$ with different distributions: (a) $\delta_{x}=6 \mathrm{~m}$ and $\operatorname{CoV}_{G}=0.1$; (b) $\delta_{x}=6 \mathrm{~m}$ and $\operatorname{CoV}_{G}=0.3$; (c) $\delta_{x}=6 \mathrm{~m}$ and $\mathrm{CoV}_{G}=0.5$; (d) $\delta_{x}=60 \mathrm{~m}$ and $\mathrm{CoV}_{G}=0.1 ;$ (e) $\delta_{x}=60 \mathrm{~m}$ and $\mathrm{CoV}_{G}=0.3$; (f) $\delta_{x}=60 \mathrm{~m}$ and $\mathrm{CoV}_{G}=0.5$.

$\mu_{D_{2}, \max }$, which is consistent with the findings in Figure 6. A greater $\mu_{D_{X, \max }}$ was corresponding with a greater $\mathrm{CoV}_{G}$ for all three distributions. Comparing between
Figures 9(a) and 9(b), it can be observed that small $\delta_{x}$ corresponded to large $\mu_{D_{X} \text { max }}$, except for the case of $\mathrm{CoV}_{G}=0.3$ under the Beta distribution. 

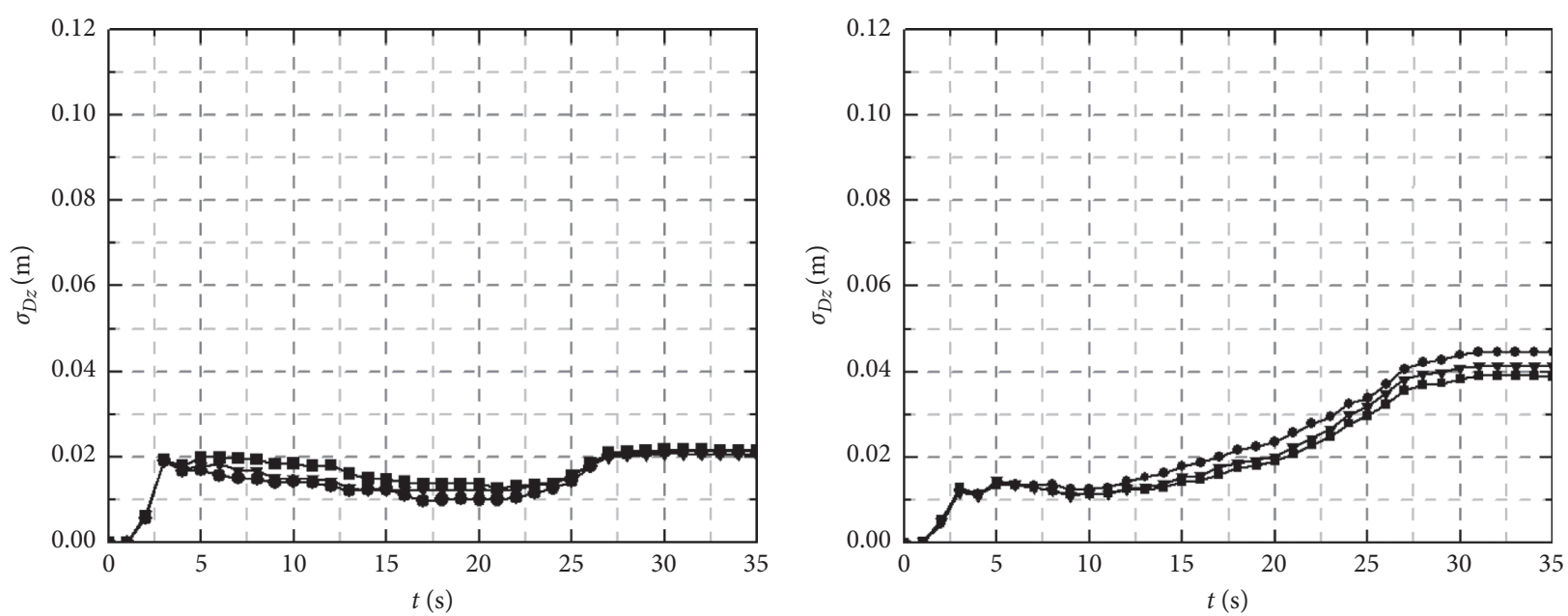

$\rightarrow$ Lognormal
$\rightarrow-$ Gamma
$\rightarrow$ Beta

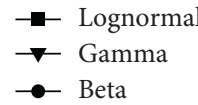

(a)

(b)
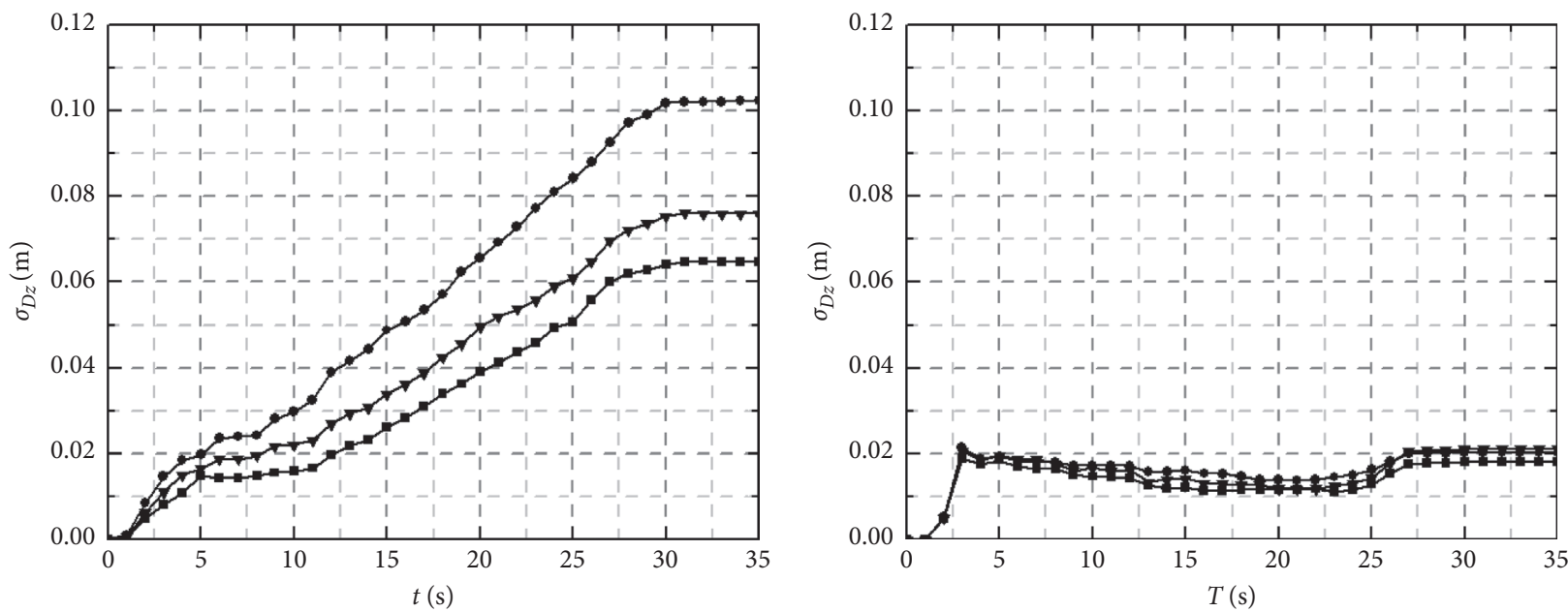

- Lognormal

$\boldsymbol{\nabla}$ Gamma

- - Lognormal

$\rightarrow$ - Gamma

$\longrightarrow$ Beta

$\multimap$ Beta

(c)

(d)

Figure 8: Continued. 


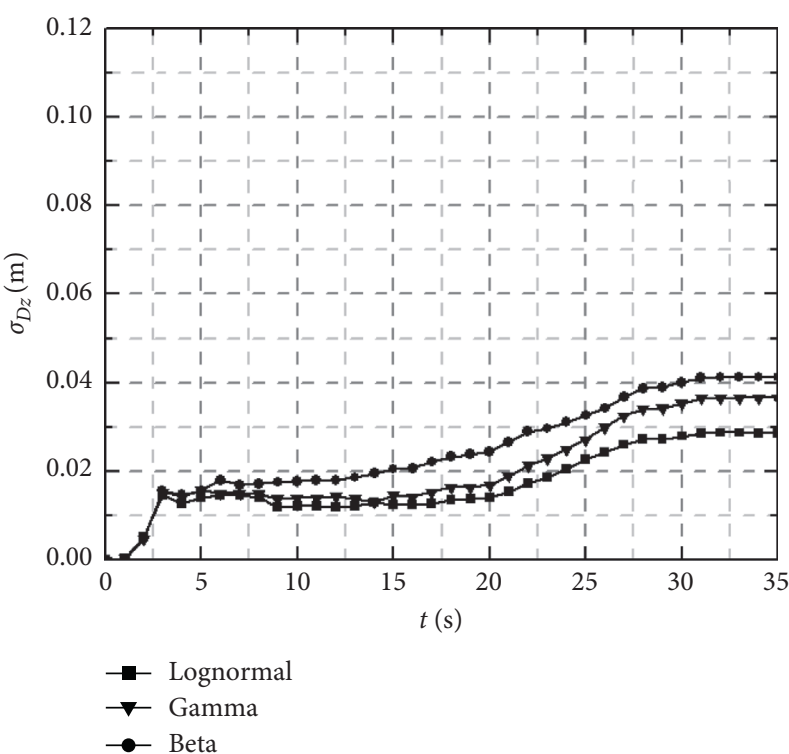

(e)

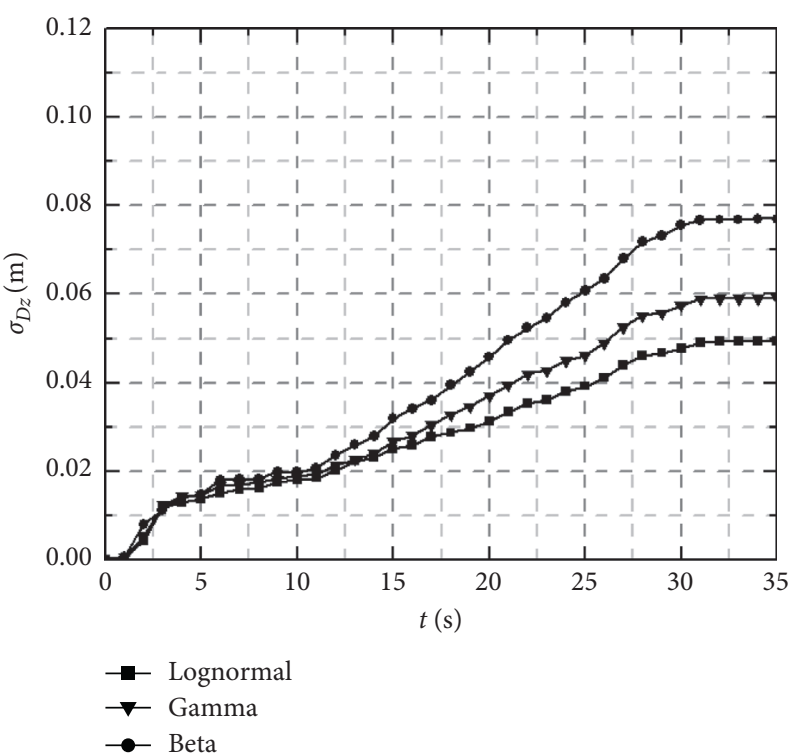

(f)

Figure 8: Time history curve of $\sigma_{z}$ with different distributions: (a) $\delta_{x}=6 \mathrm{~m}$ and $\operatorname{CoV}_{G}=0.1 ;$ (b) $\delta_{x}=6 \mathrm{~m}$ and $\operatorname{CoV}_{G}=0.3$; (c) $\delta_{x}=6 \mathrm{~m}$ and $\mathrm{CoV}_{G}=0.5$; (d) $\delta_{x}=60 \mathrm{~m}$ and $\mathrm{CoV}_{G}=0.1$; (e) $\delta_{x}=60 \mathrm{~m}$ and $\mathrm{CoV}_{G}=0.3$; (f) $\delta_{x}=60 \mathrm{~m}$ and $\mathrm{CoV}_{G}=0.5$.

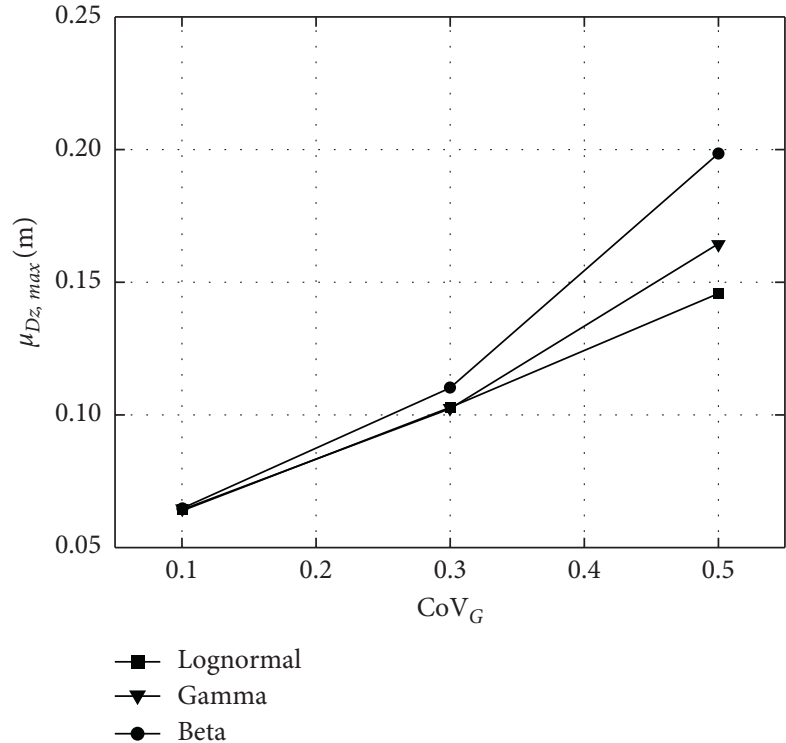

(a)

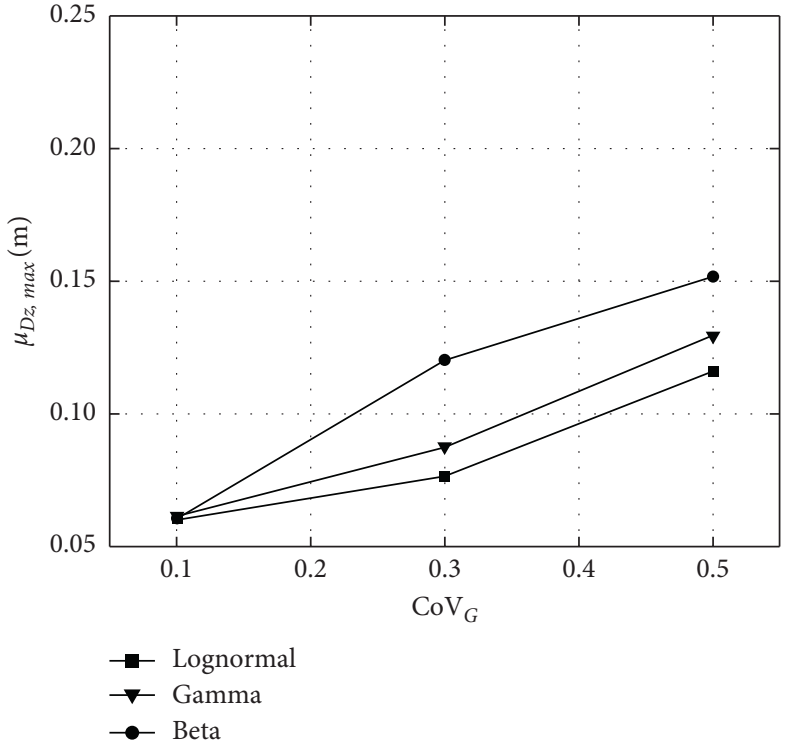

(b)

Figure 9: Variation of $\mu_{D_{z} \text {, max }}$ as a function of $\operatorname{CoV}_{G}$ : (a) $\delta_{x}=6 \mathrm{~m}$ and (b) $\delta_{x}=60 \mathrm{~m}$.

\section{Concluding Remarks}

In this study, the influence of the probability distributions of soil shear modulus on the area of liquefaction zone, the ratio of excess pore water pressure, and the ground displacement is investigated. The following conclusions can be drawn:

(1) The probability distribution type of shear modulus had no significant influence on the reduction rate of liquefaction zone and the sensitivity of the liquefaction zone to the instantaneous seismic load.
(2) Compared with the Lognormal distribution and Gamma distribution, a smaller excess pore water pressure ratio could be observed with the Beta distribution employed. The pore water pressure dissipation rate accelerated with the increase in $\mathrm{CoV}_{G}$ and was affected by the distribution type.

(3) Regarding the ground movement, the estimated horizontal displacement and settlement with Beta distribution were the worst scenario. The sensitivity of the ground horizontal displacement and 
settlement to $\mathrm{CoV}_{G}$ decreased successively for Beta, Gamma, and Lognormal distribution.

\section{Data Availability}

The data used to support the findings of this study are available from the corresponding author upon request.

\section{Conflicts of Interest}

The authors declare that they have no conflicts of interest.

\section{Acknowledgments}

The support by the National Natural Science Foundation of China (Grant no. 51808490) is greatly acknowledged.

\section{References}

[1] S. Javankhoshdel and R. J. Bathurst, "Simplified probabilistic slope stability design charts for cohesive and cohesive-frictional (c- $\phi$ ) soils," Canadian Geotechnical Journal, vol. 51, no. 9, pp. 1033-1045, 2014.

[2] S.-H. Jiang, I. Papaioannou, and D. Straub, "Bayesian updating of slope reliability in spatially variable soils with insitu measurements," Engineering Geology, vol. 239, pp. 310320, 2018.

[3] S. Jiang, J. Huang, X. Qi, and C. Zhou, "Efficient probabilistic back analysis of spatially varying soil parameters for slope reliability assessment," Engineering Geology, vol. 271, 2020.

[4] Y. F. Gao, F. Zhang, G. H. Lei, and D. Y. Li, "An extended limit analysis of three-dimensional slope stability," Géotechnique, vol. 63, no. 6, pp. 518-524, 2013.

[5] Y. Gao, F. Zhang, G. H. Lei, D. Li, Y. Wu, and N. Zhang, "Stability charts for 3D failures of homogeneous slopes," Journal of Geotechnical and Geoenvironmental Engineering, vol. 139, no. 9, pp. 1528-1538, 2013.

[6] J. Li, Y. Tian, and M. J. Cassidy, "Failure mechanism and bearing capacity of footings buried at various depths in spatially random soil," Journal of Geotechnical and Geoenvironmental Engineering, vol. 141, no. 2, 2015.

[7] S. Shu, Y. Gao, and Y. Wu, "Probabilistic bearing capacity analysis of Spudcan foundation in soil with linearly increasing mean undrained shear strength," Ocean Engineering, vol. 204, Article ID 106800, 2020.

[8] G. A. Fenton and D. V. Griffiths, "Three-Dimensional probabilistic foundation settlement," Journal of Geotechnical and Geoenvironmental Engineering, vol. 131, no. 2, pp. 232239, 2005.

[9] A. Ahmed and A.-H. Soubra, "Probabilistic analysis of strip footings resting on a spatially random soil using subset simulation approach," Georisk: Assessment and Management of Risk for Engineered Systems and Geohazards, vol. 6, no. 3, pp. 188-201, 2012.

[10] M. Uzielli and P. W. Mayne, "Load-displacement uncertainty of vertically loaded shallow footings on sands and effects on probabilistic settlement estimation," Georisk: Assessment and Management of Risk for Engineered Systems and Geohazards, vol. 6, no. 1, pp. 50-69, 2012.

[11] C. H. Juang, C. J. Chen, D. V. Rosowsky, and W. H. Tang, "CPT-based liquefaction analysis, Part 2: reliability for design,” Géotechnique, vol. 50, no. 5, pp. 593-599, 2000.
[12] M. K. Talukder and L. Chouinard, "Probabilistic methods for the estimation of seismic Fa and Fv maps-application to montreal," Bulletin of Earthquake Engineering, vol. 14, no. 2, pp. 345-372, 2016.

[13] K. O. Cetin, E. Altinci, and H. T. Bilge, "Probability-based assessment of number of equivalent uniform stress cycles," Soil Dynamics and Earthquake Engineering, vol. 143, no. 6, 2021.

[14] D. V. Griffiths and G. A. Fenton, "Bearing capacity of spatially random soil:The undrained clay Prandtl problem revisited," Géotechnique, vol. 51, no. 8, pp. 351-359, 2001.

[15] J. H. Li, M. J. Cassidy, Y. Tian, J. Huang, A. V. Lyamin, and M. Uzielli, "Buried footings in random soils: comparison of limit analysis and finite element analysis," Georisk: Assessment and Management of Risk for Engineered Systems and Geohazards, vol. 10, no. 1, pp. 55-65, 2015.

[16] S.-H. Jiang and J. Huang, "Modeling of non-stationary random field of undrained shear strength of soil for slope reliability analysis," Soils and Foundations, vol. 58, no. 1, pp. 185-198, 2018.

[17] R. Popescu, G. Deodatis, and A. Nobahar, "Effects of random heterogeneity of soil properties on bearing capacity," Probabilistic Engineering Mechanics, vol. 20, no. 4, pp. 324-341, 2005.

[18] R. Jimenez and N. Sitar, "The importance of distribution types on finite element analyses of foundation settlement," Computers and Geotechnics, vol. 36, no. 3, pp. 474-483, 2009.

[19] Y. Wu, H. Bao, J. Wang, and Y. Gao, "Probabilistic analysis of tunnel convergence on spatially variable soil: the importance of distribution type of soil properties," Tunnelling and Underground Space Technology, vol. 109, no. 1, 2021.

[20] Y. Wang, S. Shu, and Y. Wu, "Reliability analysis of soil liquefaction considering spatial variability of soil property," Journal of Earthquake and Tsunami, 2021, Article ID 2250002, DOI: $10.1142 /$ S1793431122500026.

[21] M. Azadi and S. M. Hosseini, "Analyses of the effect of seismic behavior of shallow tunnels in liquefiable grounds," Tunnelling and Underground Space Technology, vol. 25, no. 5, pp. 543-552, 2010.

[22] S.-H. Jiang and J.-S. Huang, "Efficient slope reliability analysis at low-probability levels in spatially variable soils," Computers and Geotechnics, vol. 75, pp. 18-27, 2016.

[23] R. Popescu, J. H. Prevost, and G. Deodatis, "Effects of spatial variability on soil liquefaction: some design recommendations," Géotechnique, vol. 47, no. 5, pp. 1019-1036, 1997. 